\section{Transfusion Medicine and Hemotherapy}

Received: March 8, 2018 Accepted: May 26, 2018 Published online: January 29, 2019

\title{
The Remarkable Journey of a Low-Frequency Alloantibody
}

\author{
Adrian Bachofner ${ }^{a, b}$ Tanja Rüfli ${ }^{b} \quad$ Andreas Holbro ${ }^{a, b}$ Hein Hustinx ${ }^{c}$ \\ Sofia Lejon Crottet ${ }^{c}$ Matyas Escedi ${ }^{a, b}$ Andreas Buser ${ }^{a, b}$ Laura Infanti ${ }^{a, b}$ \\ ${ }^{a}$ Regional Blood Transfusion Center, Swiss Red Cross, Basel, Switzerland; 'b Division of Hematology, University Hospital Basel, \\ Basel, Switzerland; 'S Swiss Immunohematology Reference Laboratory, Interregional Blood Transfusion, Swiss Red Cross, Basel, \\ Switzerland
}

\section{Keywords}

Alloimmunization · Anti-Diego A · Blood transfusion · Low-frequency alloantibody

\begin{abstract}
Herein we describe a case of febrile non-hemolytic reaction (FNHTR) in a 64-year-old male 20 min after the transfusion of one red blood cell unit. 20 days prior the patient had undergone an allogeneic hematopoietic stem cell transplantation (HCT) from an unrelated donor with minor $A B O$ disparity. The patient had been treated for plasma cell myeloma with multiple transfusions in the past, but no transfusion reactions or alloimmunization had been reported.
\end{abstract}

(c) 2019 S. Karger GmbH, Freiburg

\section{Introduction}

The Diego (Di) blood group system comprises 22 antigens located on the band 3 protein $[1,2]$, most of which are low-prevalence antigens. $\mathrm{Di}^{\mathrm{a}}$, a low-prevalence blood group itself, is expressed in only $0.01 \%$ of Caucasians but is more frequent in some populations, i.e. in subjects of Asian and South American descent. Rates of alloimmunization against $\mathrm{Di}^{\mathrm{a}}$ in multitransfused patients in Brazil, for example, have been estimated to be as high as 3.6\%, due to the higher frequency of the $\mathrm{Di}^{\mathrm{a}}$ antigen in Brazilian blood donors $[3,4]$.

\section{KARGER}

(c) 2019 S. Karger GmbH, Freiburg

\section{Case Report}

We describe a transfusion reaction that was classified as febrile non-hemolytic (FNHTR) in a Swiss 64-year-old male patient regularly transfused during treatment for plasma cell myeloma. 20 days prior to the event, he had undergone allogeneic hematopoietic stem cell transplantation from a matched unrelated donor with minor ABO disparity. Despite a long-standing medical history, including autologous stem cell transplantation in Brazil in 2011, no transfusion reactions or alloimmunization had so far been reported in the patient's history.

The symptoms of the transfusion reaction developed shortly after initiation of the transfusion of a red blood cell (RBC) unit, and included an increase of the core temperature to $38.2{ }^{\circ} \mathrm{C}$, slight shivers, and a temporary drop of the oxygen saturation with no signs of bronchospasm on auscultation. No chest X-ray was performed. The symptoms were responsive to acetaminophen, clemastine, pethidine, and methylprednisolone. The RBC unit was the only blood product given on this day and was issued based on a negative type and screen, according to internal routine procedures. Of interest, the blood donor of the involved blood product was a 21-year-old Swiss male whose mother is of Chinese origin.

Laboratory investigations showed a slight increase of LDH (273 $\mathrm{U} / \mathrm{l}$; upper cut-off limit $225 \mathrm{U} / \mathrm{l}$ ) and of bilirubin (from $8 \mu \mathrm{mol} / \mathrm{l}$ to $15 \mu \mathrm{mol} / \mathrm{l})$ that remained however within the normal range $(<24$ $\mu \mathrm{mol} / \mathrm{l})$. A haptoglobin measurement was not performed. Of note, the hemoglobin level dropped from a pre-transfusion value of 73 $\mathrm{g} / \mathrm{l}$ to a post-transfusion level of $67 \mathrm{~g} / \mathrm{l}$, suggesting a shortened survival time of the transfused erythrocytes.

On immunohematological workup, the alloantibody identification test (ID-DiaPanel; Bio Rad, Cressier, Switzerland) as well as the direct antiglobulin tests before and after transfusion were negative. However, the crossmatch (gel-based indirect antiglobulin test) performed on both a pre-transfusion and post-transfusion sample showed incompatibility with the RBC unit administered (3+ and $2+$ respectively), suggesting the presence of an alloantibody against 
Fig. 1. The photos illustrate erythrophagocytosis by monocytes.

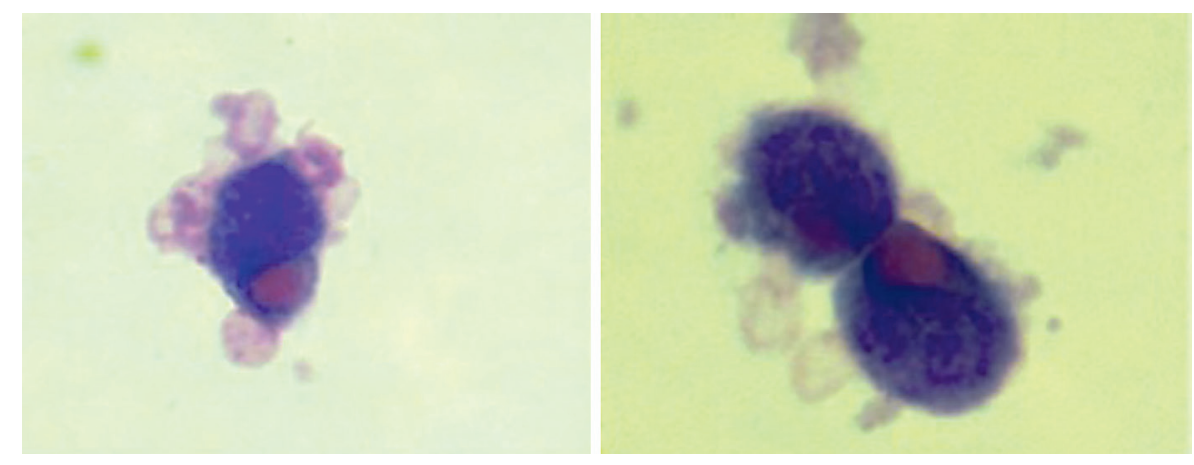

a low-prevalence RBC antigen in the patient's serum. A post-transfusion serum sample of the patient and a sample of the involved $\mathrm{RBC}$ unit were sent to the Swiss immunohematology reference laboratory for further investigation. An anti- $\mathrm{Di}^{\mathrm{a}}$ alloantibody in the patient's serum could be identified using an extended panel of test erythrocytes, and the presence of the $\mathrm{Di}^{\mathrm{a}}$ antigen on the surface of the transfused RBC was confirmed by serological determination.

In order to evaluate the potential clinical significance of the alloantibody, a monocyte monolayer assay (MMA) was performed. In this assay, test RBCs expressing the antigen in question are sensitized with the recipient's serum before being incubated with a culture of monocytes harvested from a healthy donor. The degree of erythrophagocytosis (Monocyte Index) is then evaluated by microscopy. In our case, the MMA showed a Monocyte Index of $46 \%$, highly indicative of the alloantibody's clinical significance $(>5 \%$ is considered as clinically significant) (fig. 1).

In the following weeks, all RBC units issued to the patient were tested by crossmatch, and all subsequent transfusion episodes were uneventful.

\section{Discussion}

This case is illustrative of immunohematology issues that can be relevant in daily transfusion practice. First, it provides an example of type and screen failure in detecting clinically relevant antibodies directed against low-frequency antigens. Anti-Di ${ }^{\mathrm{a}}$ alloantibodies are likely to escape antibody screening in most European transfusion laboratories, because usually no $\mathrm{Di}^{\mathrm{a}}$-positive $\mathrm{RBCs}$ are included in the panels used for type and screen and for alloantibody identification, and because many centers, like ours, issue compatible $\mathrm{RBC}$ units based on negative results of type and screen without direct crossmatch. Second, our case highlights the possible implications of the ethnic disparity between blood do- nors and recipients of transfusions. The $\mathrm{RBC}$ transfusions received by our patient some years before in Brazil are very likely responsible for the development of the anti- $\mathrm{Di}^{\mathrm{a}}$ alloantibody. The ethnical background of the blood donor implicated in the transfusion reaction (mother of Asian descent) explains the presence of $\mathrm{Di}^{\mathrm{a}}$ antigens on the surface of his erythrocytes, which boostered the alloantibody.

Transfusions of $\mathrm{Di}^{\mathrm{a}}$-incompatible $\mathrm{RBC}$ units were described to cause very variable clinical manifestations, ranging from uneventful to severe or delayed transfusion reactions $[5,6]$. In our case, due to the mild respiratory symptoms and the absence of overt hemolysis, the transfusion reaction was classified as a FNHTR, when in fact an immediate, albeit mild hemolytic reaction contributed to the findings, as demonstrated by the lack of adequate hemoglobin increase after the transfusion and markedly increased phagocytic index in the MMA.

The MMA has proven to be a reliable in vitro tool for predicting the fate of transfused RBCs and for estimating the risk for a hemolytic transfusion reaction in alloimmunized subjects and in cases of materno-fetal blood group incompatibility [7]. Interestingly, in our patient a clear discrepancy was observed between the strongly reactive result of the MMA and the mild clinical manifestations. It is well described that a negative MMA reliably excludes the presence of clinically relevant alloantibodies, but, as demonstrated in our case, the strength of MMA reactivity seems not necessarily to correlate with the severity of symptoms.

\section{Disclosure Statement}

All authors declare that they have no conflict of interest.

\section{References}

1 Dean L: Blood Groups and Red Cell Antigens. Bethesda, National Center for Biotechnology Information, 2005.

2 Storry JR, Castilho L, Daniels G, Flegel WA, Garratty G, Francis CL, Moulds JM, Moulds JJ, Olsson ML, Poole J, Reid ME, Rouger P, van der Schoot E, Scott M, Smart E, Tani Y, Yu LC, Wendel S, Westhoff C, Yahalom V, Zelinski T.: International Society of Blood Transfusion Working Party on red cell immunogenetics and blood group terminology: Berlin report. Vox Sang 2011; 101:77-82.

3 Zago-Novaretti MC: Anti-Diego in multitransfused patients. Rev Paulista Med 1992; 110:IH52 (abstract).

4 Daniels G: Human Blood Groups, 2nd ed. Oxford, Blackwell Science, 2002.

5 Joyce AJ, Quantock KM, Bahn R, Liew YW: Hemolytic transfusion reaction attributable to anti-Dia. Immunohematology 2017;33:68.

6 Reid M, Lomas-Francis C, Olsson M: The Blood Group Antigen FactsBook, 3rd ed. London, Academic Press, 2012.

7 Arndt PA, Garratty G: A retrospective analysis of the value of monocyte monolayer assay results for predicting the clinical significance of blood group alloantibodies. Transfusion 2004;44:1273-1281. 